J Pediatr Res 2021; 8: 479-484

DOI: $10.4274 / j p r . g a l e n o s .2021 .79446$

The change made in the article titled "Risk Factors of Hyponatremia in Children with Lower Respiratory Tract Infection (LRTI)" in the research articles section published in JPR 2021;8(4) are as follows.

Page 479

\title{
Published;
}

${ }^{1}$ All India Institute of Medical Sciences, Department of Pediatrics and Neonatology, New Delhi, India

\section{Reported Correction;}

${ }^{1}$ All India institute of Medical Sciences, Department of Pediatrics and Neonatology, Bhubaneswar, India

\section{Published;}

Address for Correspondence

All India Institute of Medical Sciences, Department of Pediatrics and Neonatology, New Delhi, India

\section{Reported Correction;}

Address for Correspondence

All India institute of Medical Sciences, Department of Pediatrics and Neonatology, Bhubaneswar, India 